\title{
Renal Denervation for Treating Resistant Hypertension: Current Evidence and Future Insights from a Global Perspective
}

\author{
Y. Castro Torres ${ }^{1}$ and Richard E. Katholi ${ }^{2}$ \\ ${ }^{1}$ Facultad de Medicina, Universidad de Ciencias Médicas “Dr. Serafín Ruiz de Zárate Ruiz”, Santa Clara, 50100 Villa Clara, Cuba \\ ${ }^{2}$ Southern Illinois University School of Medicine and Prairie Education and Research Cooperative, Springfield, IL 62701, USA
}

Correspondence should be addressed to Richard E. Katholi; rkatholi@prairieheart.com

Received 29 August 2013; Revised 14 October 2013; Accepted 18 October 2013

Academic Editor: Kazushi Tsuda

Copyright (c) 2013 Y. Castro Torres and R. E. Katholi. This is an open access article distributed under the Creative Commons Attribution License, which permits unrestricted use, distribution, and reproduction in any medium, provided the original work is properly cited.

\begin{abstract}
Adequate blood pressure control represents an important goal for all physicians due to the complications of hypertension which reduce patients' quality of life. A new interventional strategy to reduce blood pressure has been developed for patients with resistant hypertension. Catheter-based renal denervation has demonstrated excellent results in recent investigations associated with few side effects. With the growing diffusion of this technique worldwide, some medical societies have published consensus statements to guide physicians how to best apply this procedure. Questions remain to be answered such as the long-term durability of renal denervation, the efficacy in patients with other sympathetically mediated diseases, and whether renal denervation would benefit patients with stage 1 hypertension.
\end{abstract}

\section{Introduction}

Approximately $34 \%$ of adults worldwide have hypertension [1]. Hypertension is the leading cause of global mortality accounting for $13 \%$ of deaths [2]. In the United States, there is an estimated of 77.9 million adults $\geq 20$ years of age with this condition [3]. Hypertension management utilizes the strategies of lifestyle modification and pharmacological treatment. However, in many patients, blood pressure (BP) control is not accomplished.

Resistant hypertension (RH) is defined when a patient taking three or more antihypertensive drugs, including a diuretic, at optimal tolerated doses, and still maintains BP values $>140 / 90 \mathrm{mmHg}[4,5]$. Prevalence of $\mathrm{RH}$ is not well established but some statistics reveal that it represents 13\% of hypertensive patients [6]. Data from National Health and Nutrition Examination Survey among United States adults reveal the criteria for RH which were found in $8.9 \%$ of hypertensive patients [3]. The causes of $\mathrm{RH}$ are diverse and it may involve multiple mechanisms (see Table 1) $[4,5]$. RH worsens the prognosis of hypertensive patients. The rate of fatal and nonfatal cardiovascular events in patients with $\mathrm{RH}$ is three to six times higher than that of controlled hypertensive individuals. $\mathrm{RH}$ increases the risk of left ventricular hypertrophy, microalbuminuria, kidney failure, endothelial dysfunction, carotid artery stiffness, and atherosclerosis [7].

Recently, a catheter-based technique using radiofrequency to destroy the renal nerves has opened a new novel approach to treat $\mathrm{RH}$ [8-11]. Clinical trials have shown a reduction in $\mathrm{BP}$ with minimal side effects $[12,13]$. In this paper we propose to review the current evidence and status of catheter-based renal denervation (RDN) in the treatment of $\mathrm{RH}$ and its future as a therapy from a global perspective.

\section{Renal Sympathetic Nerves}

The pathogenesis of essential hypertension is multifactorial. However, hyperactivity of the sympathetic nervous system plays an important role in its development and progression [14]. The kidneys have an important interrelationship with the sympathetic nervous system. As shown in Figure 1, there are two types of renal sympathetic nerve fibers: the afferent and efferent nerves are located immediately adjacent to the wall of the renal artery. The afferent renal sympathetic nerves have cell bodies located in the ipsilateral dorsal root ganglia and modulate central sympathetic outflow by sending sensorial information from chemoreceptors and mechanoreceptors in the renal tissue. Renal injuries including ischemia and 
TABLE 1: Causes of RH.

\begin{tabular}{ll}
\hline Improper blood pressure measurement & Associated conditions \\
\hline Volume overload and pseudotolerance & (i) Obesity \\
(i) Excess sodium intake & (ii) Excess alcohol intake \\
(ii) Volume retention from kidney disease & (iii) Physical inactivity \\
& (iv) Low-fiber diet \\
\hline Drug-induced or other causes & Secondary causes of RH \\
\hline (i) Nonadherence & (i) Obstructive sleep apnea \\
(ii) Inadequate doses & (ii) Primary aldosteronism \\
(iii) Inappropriate combinations & (iii) Pheochromocytoma \\
(iv) Cyclosporine and tacrolimus & (iv) Hyperparathyroidism \\
(v) Cocaine, amphetamines, and other illicit drugs & (v) Aortic coarctation \\
(vi) Sympathomimetics (decongestants, anorectics) & (vi) Renal parenchymal disease \\
(vii) Herbal compounds & (vii) Renal artery stenosis \\
(viii) Adrenal steroids & (viii) Intracranial tumor \\
(ix) Nonsteroidal anti-inflammatory drugs; aspirin, cyclooxygenase 2 inhibitors & \\
(x) Erythropoietin & \\
(xi) Licorice (including some chewing tobacco) & \\
(xii) Oral contraceptives &
\end{tabular}

hypoxia increase afferent renal sympathetic nerves activity resulting in increased peripheral sympathetic nerve activity with resultant arterial vasoconstriction and subsequent hypertension.

The efferent renal sympathetic nerves originate from postganglionic sympathetic neurons and transmit signals from the central sympathetic nervous system to the renal vasculature, tubules, and juxtaglomerular apparatus. Efferent renal sympathetic activity is moderated by renorenal reflexes and central sympathetic nervous system outflow. Elevated renal efferent nerve activity increases sodium reabsorption, increases renin release, and causes renal arterial vasoconstriction, factors which cause hypertension [15-18].

\section{Renal Denervation}

The importance of the renal nerves in treating hypertension has evolved over the years. Nephrectomy in humans resulted in a lowering of blood pressure and a reduction of muscle sympathetic nerve activity. Other studies confirmed this hypothesis through surgical denervation [15]. The use of radical surgical sympathectomy and therapeutic splanchnicectomy was abandoned in the 1960s because these methods were associated with severe side effects such as postural hypotension, syncope, impotence, and mobility disturbance. Another factor which led to abandoning these surgical approaches was the development of modern pharmacological antihypertensive medications $[8,19,20]$.

A new approach to disrupt renal sympathetic nerves has been developed without affecting other abdominal, pelvic, or lower extremities innervations. This involves ablation of both afferent and efferent renal sympathetic nerves with a radiofrequency-emitting catheter inserted percutaneously into the renal artery via transfemoral approach to reduce BP in patients with RH. The Symplicity catheter system is now available in many countries. This device consists of a 5-F blind-ending catheter that houses a flexible radiofrequency wire. The back end portion of the catheter handle connects to a radiofrequency generator that supplies power. The procedure is performed under local anesthesia and sedation. Catheter control by the handle allows bringing this device into contact with the endothelial surface of the artery. Four to six 2-minute treatments are delivered at different locations longitudinally and rotationally in order to achieve a helical pattern of ablation within each renal artery. The energy delivered is $5 \mathrm{~W}$ to $8 \mathrm{~W}$. Both renal arteries are treated on the same day. Before this procedure, the patient receives anticoagulation and intravenous administration of $200 \mu \mathrm{g}$ of nitroglycerin $[12,21]$.

\section{Evidence in Favor of Catheter-Based RDN}

There are several studies in patients with $\mathrm{RH}$ which have shown a reduction in $\mathrm{BP}$ and minimal side effects with RDN. Symplicity HTN-1 and HTN-2 trials provide much information and are compared in Table 2. Symplicity HTN-1 initially was conducted in 45 patients with $\mathrm{RH}$. The mean values of baseline BP were $177 / 101 \mathrm{mmHg}$. In the first six months after RDN, there was a mean decrease in systolic and diastolic BP of $25 \mathrm{mmHg}$ and $11 \mathrm{mmHg}$, respectively. When the sample size was increased to 153 patients, the mean decrease in systolic and diastolic BP was $32 \mathrm{mmHg}$ and $14 \mathrm{mmHg}$, respectively. In 10 of the patients, a $47 \%$ reduction in renal norepinephrine spillover one month after RDN was measured confirming renal efferent nerve attenuation. The side effects of RDN were one case of artery dissection and another with a prior renal artery stenosis. A small number of patients and no control group were the main limitations of this study [12].

Symplicity HTN-2 was the next study performed to determine the utility of the catheter-based RDN to reduce $\mathrm{BP}$ in patients with $\mathrm{RH}$. It was an international multicenter 


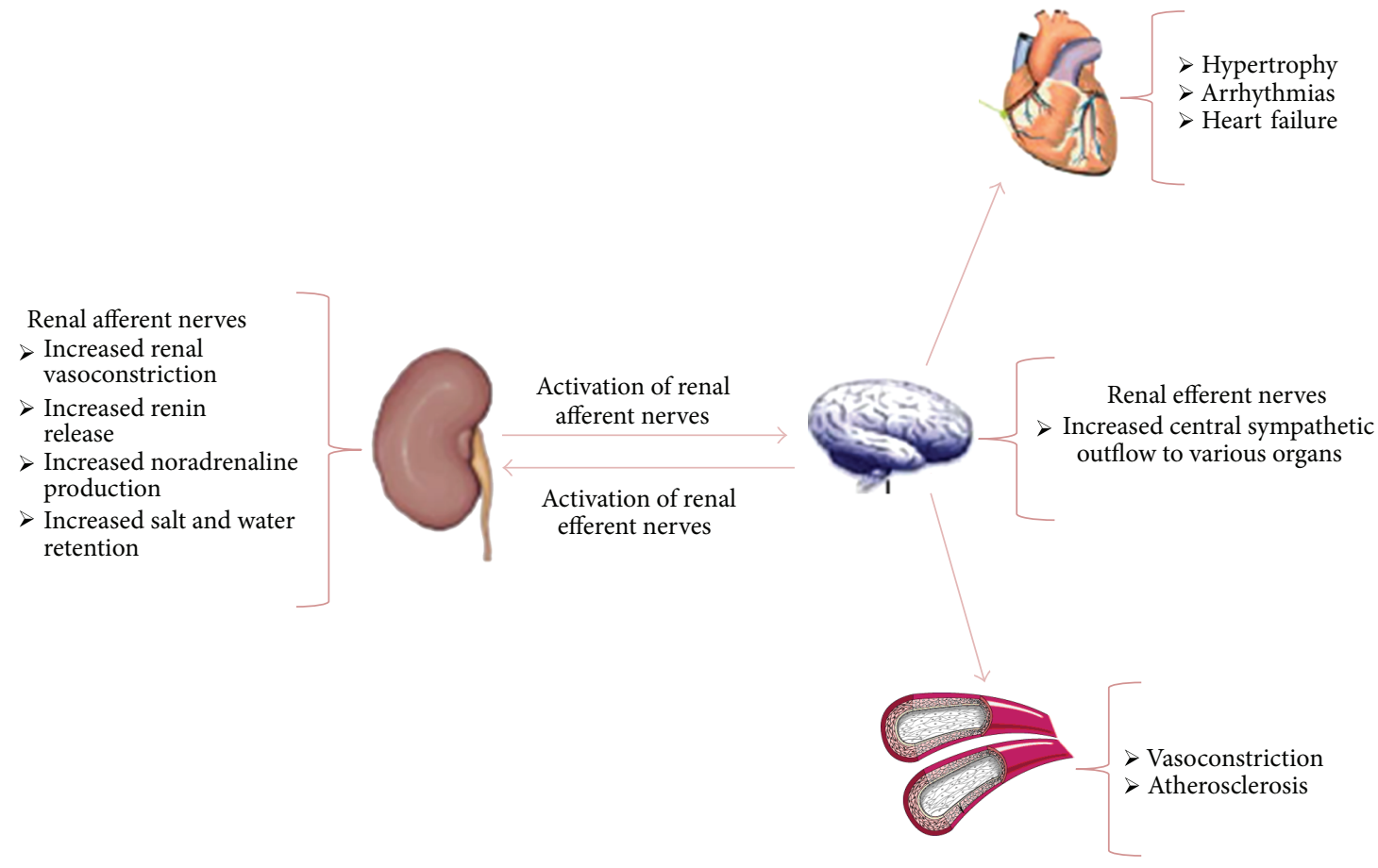

FIGURE 1: Activation of renal nerves and their actions in different organs. Stimulation of the renal sympathetic efferent nerves causes renin release, sodium retention, and reduced renal blood flow, factors which cause hypertension. Elevated afferent renal sensory nerve signals are centrally integrated in the hypothalamic region and result in increased sympathetic outflow directed to various regions, including the kidneys, the skeletal muscle vasculature, and the heart, which contributes substantially to elevated peripheral vascular resistance, vascular remodeling, and left ventricular hypertrophy.

TABLE 2: Comparison between Symplicity HTN-1 and HTN-2 trials.

\begin{tabular}{|c|c|c|c|c|c|}
\hline Trial & $\begin{array}{c}\text { Patients } \\
\text { characteristics }\end{array}$ & Study design & $\begin{array}{l}\text { Mean values of } \\
\text { baseline BP }\end{array}$ & Main results & Side effects \\
\hline $\begin{array}{l}\text { Symplicity } \\
\text { HTN-1 }\end{array}$ & $\begin{array}{l}45 \text { patients, mean } \\
\text { age } 58 \pm 9 \text { years }\end{array}$ & $\begin{array}{c}\text { Proof-of-principle, } \\
\text { nonrandomized }\end{array}$ & $\begin{array}{l}177 / 101 \pm \\
20 / 15 \mathrm{mmHg}\end{array}$ & $\begin{array}{l}\text { At } 6 \text { months showed a } \\
\text { mean decrease in systolic } \\
\text { and diastolic BP of } \\
25 \mathrm{mmHg} \text { and } 11 \mathrm{mmHg} \\
\text { respectively. Reduction in } \\
\text { renal norepinephrine } \\
\text { production by } 47 \% \text { in } 10 \\
\text { patients }\end{array}$ & $\begin{array}{l}\text { The side effects were one } \\
\text { case of renal artery } \\
\text { dissection and another } \\
\text { with a prior renal artery } \\
\text { stenosis. }\end{array}$ \\
\hline $\begin{array}{l}\text { Symplicity } \\
\text { HTN-2 }\end{array}$ & $\begin{array}{l}106(52 \mathrm{RD}, 54 \\
\text { controls). Mean } \\
\text { age } 58 \pm 12 \text { years in } \\
\text { both groups }\end{array}$ & $\begin{array}{l}\text { Randomized, } \\
\text { controlled; } \\
\text { unblinded }\end{array}$ & $\begin{array}{l}\text { RD group: } 178 / 97 \pm \\
\text { 18/16 mmHg } \\
\text { Control group: } \\
178 / 98 \pm \\
16 / 17 \mathrm{mmHg}\end{array}$ & $\begin{array}{l}\text { RD group had mean office } \\
\text { BP reduction of } 20 / 7 \text { and } \\
32 / 12 \text { mmHg by } 1 \text { and } 6 \\
\text { months following RD. } \\
\text { Nineteen patients had a } \\
\text { reduction in systolic } \mathrm{BP} \text { to } \\
\text { less than } 140 \mathrm{mmHg} \text { in this } \\
\text { same group }\end{array}$ & $\begin{array}{l}\text { One case of } \\
\text { postprocedural } \\
\text { hypotension. A patient } \\
\text { with single femoral } \\
\text { artery pseudoaneurysm } \\
\text { and } 7 \text { patients developed } \\
\text { intraprocedural } \\
\text { bradycardia }\end{array}$ \\
\hline
\end{tabular}

randomized trial. A total of 106 patients with $\mathrm{RH}$ and preserved renal function were enrolled. In this study, the participants were divided into 2 groups. The first group $(n=52)$ was randomly assigned to undergo RDN with the Symplicity device. The second $(n=54)$ continued with antihypertensive therapy alone. The mean baseline values in both groups were $178 / 97$ and $178 / 98 \mathrm{mmHg}$, respectively. The results showed that the RDN group had a mean office $\mathrm{BP}$ reduction of 20/7 and 32/12 $\mathrm{mmHg}$ by 1 and 6 months. Nineteen of these patients had a reduction in systolic BP to less than $140 \mathrm{mmHg}$. 
Adverse events included had one case of postprocedural hypotension which required a reduction in antihypertensive drugs, a single femoral artery pseudoaneurysm, and 7 patients required atropine due to intraprocedural bradycardia. Renal function showed no significant differences between groups at six months [13].

One-year results have been published of the patients enrolled in Symplicity HTN-2. The mean fall in systolic BP at 12 months after the procedure was $28 \mathrm{mmHg}$. Knowing the long-term benefit of this procedure will determine its application in clinical practice [22].

A number of isolated cases have reported the utility of RDN. Ong et al. published a case report of a 76-year-old male subject diagnosed with $\mathrm{RH}$ treated with percutaneous RDN with resultant marked lowering of BP by six months. It was possible to reduce antihypertensive drugs from five to one in the patient [23]. Similar findings were found with RDN in a 59-year-old male with longstanding RH and 2 previous episodes of transient ischemic attacks. The researchers observed a reduction in serum noradrenaline levels and plasma renin activity with an improvement in baroreflex sensitivity [21].

Another prospective study was carried out in China with the aim to evaluate the safety and short-term efficacy of RDN therapy in 8 patients ( 6 males and 2 females). One month and three months after RDN, mean systolic and diastolic BP decreased significantly compared with baseline. There were no complications or significant changes in renal function [24]. The utility of RDN has been shown in other settings. In order to determine the effects of this procedure on central hemodynamics in patients with $\mathrm{RH}, \mathrm{RDN}$ was performed in 110 patients and 10 controls. The main findings were a significant reduction in central aortic $\mathrm{BP}$ in the RDN group from $167 / 92 \mathrm{mmHg}$ to $149 / 88 \mathrm{mmHg}, 147 / 85 \mathrm{mmHg}$, and $141 / 85 \mathrm{mmHg}$ at 1,3 , and 6 months $(P<0.001)$, respectively. Aortic pulse pressure decreased from $76.2 \pm 23.3 \mathrm{mmHg}$ to $61.5 \pm 17.5 \mathrm{mmHg}, 62.7 \pm 18.1 \mathrm{mmHg}$, and $54.5 \pm 15.7 \mathrm{mmHg}$ 1,3 , and 6 months after $\operatorname{RDN}(P<0.001)$, respectively. This investigation was the first to show that RDN can improve central hemodynamics. This study also reported significant improvement in arterial stiffness in patients treated with RDN [25].

Variability of BP is an independent factor that contributes to organ damage. Previously, it has been demonstrated that an increase in sympathetic nervous system activity is linked with $\mathrm{BP}$ variability. Zuern et al. conducted an investigation which enrolled 11 patients with $\mathrm{RH}$. The mean age was $68.9 \pm 7.0$ years, baseline systolic BP was $189 \pm 23 \mathrm{mmHg}$, and patients were on $5.6 \pm 2.1$ antihypertensive drugs. Six months after $\mathrm{RDN}$, a reduction in BP variability was observed. Previously, a reduction in $\mathrm{BP}$ variability has only been demonstrated with the administration of calcium antagonist drugs. This study demonstrated a reduction in BP variability with RDN. The authors suggest that identification of patients with elevated BP variability may be useful when selecting patients who would benefit from RDN. Patients with elevated BP variability are at increased risk for stroke and transient ischemic attacks. Thus, RDN in these patients might reduce the incidence of these conditions [26].
Recently, the effects of RDN were assessed in 10 patients with severe hypertension and sleep apnea. After RDN, systolic and diastolic BP were decreased by $34 / 13 \mathrm{mmHg}$ at 3 and 6 months. Also, a decrease in apnea-hypopnea index and significant decreases in plasma glucose concentration and glycated hemoglobin levels at 6 months were observed [27]. This study suggests that a reduction in sympathetic nervous system activity by RDN reduces serum glucose levels possibly by decreasing insulin resistance. The benefit of $\mathrm{RDN}$ in type 2 diabetic patients with hypertension merits further study. This investigation also suggests that patients with sleep apnea intolerant to continuous positive airway pressure are a subgroup which could benefit from RDN.

\section{Eligible Patients for RDN}

Based on the results from catheter-based RDN to reduce BP in patients with $\mathrm{RH}$, some medical societies have developed guidelines for physicians and interventional practitioners on the proper indications for this technique. Although this approach is new, its availability has grown quickly around the world. Evaluation of benefits/risk ratio with this procedure was the main element taken into account to develop these guidelines or consensus. In 2012, the French Societies of Hypertension, Cardiology and Radiology proposed to limit RDN to patients with essential hypertension uncontrolled by four or more antihypertensive drugs; one of these drugs should be a diuretic or spironolactone. The patients should have a measurement of office blood BP over 160 and/or $100 \mathrm{mmHg}$ confirmed by ambulatory BP measurement. The ambulatory BP should be more than 135/85 $\mathrm{mmHg}$ during the daytime period. These experts also recommended monitoring of BP, renal function, and anatomy of renal arteries 12 months and 36 months after procedure. It was emphasized that pharmacological treatment of hypertension should not be interrupted after RDN because the BP often decreases slowly over time after RDN. Since RDN is a complex procedure, it should be performed by interventionists with experience in this field [28].

The European Society of Cardiology also published a consensus statement regarding the use of catheter-based $\mathrm{RDN}$ for the treatment of hypertension [29]. Patients eligible to receive this procedure should meet the following criteria: office-based BP $\geq 160 \mathrm{mmHg}$ ( $\geq 150 \mathrm{mmHg}$ in patients with type 2 diabetes), three or more antihypertensive drugs in adequate, including use of a diuretic, having attempted to modify BP with lifestyle changes, secondary hypertension having been excluded, pseudoresistance having been excluded with the use of ambulatory blood-pressure monitoring (ABPM), patients having preserved renal function (glomerular filtration rate $\geq 45 \mathrm{~mL} / \mathrm{min} / 1.73^{2}$ ), absence of polar or accessory arteries, no renal artery stenosis, and no prior renal revascularization.

In summary, hypertensive patients being considered for RDN should not be considered to be resistant unless pseudoresistance has been excluded with the use of ABPM and they have been evaluated for sleep apnea and secondary causes of hypertension. 


\section{Unanswered Questions}

Although investigations have demonstrated the efficacy of $\mathrm{RDN}$ to decrease BP in patients with $\mathrm{RH}$, there are still unanswered questions which should be addressed in order to increase our knowledge about this topic and modify future guidelines. It is important to determine the durability of $\mathrm{RDN}$. Available data support the efficacy of this procedure to at least 2 years [30]. Further followup will answer whether this technique is effective after this time. However, a growing number of recent studies have shown that RDN has little blood pressure lowering effect in many patients and that there is no reliable method to predict success or failure in the clinical setting. Developing methods to select RH patients with hyperactivity of the sympathetic nervous system who would likely respond to RDN merits further investigations. Also, it still has not been established if there is a correlation between lower BP after RDN and an improvement in cardiovascular outcomes in patients with heart failure, coronary artery disease, and other conditions which are worsened by hypertension.

\section{Perspectives}

Many patients could benefit from RDN. A concern about using ABPM in selecting $\mathrm{RH}$ patients is the additional cost of this procedure. In a recent work, Geisler et al. found that RDN can reduce the risk of stroke, myocardial infarction, coronary heart disease, heart failure, and end-stage renal disease in a state-transition model. They also established that over a wide range of assumptions, RDN is a cost-effective strategy for $\mathrm{RH}$. However, the costs of RDN are $\$ 12,500$ (one-time material and procedure cost; $\$ 8,000$ to $\$ 15,000$ ) [31]. This limits the ability to offer this procedure to patients in underdeveloped countries. Another study supports the idea that RDN is a cost-effective intervention for patients with $\mathrm{RH}$. The authors suggest that potential lifetime cost-effectiveness ratios may be increased when the procedure is performed earlier in $\mathrm{RH}$ patients [32].

Recently, 46 patients underwent RDN to investigate the effect on BP, on left ventricular hypertrophy, and systolic and diastolic functions in patients with $\mathrm{RH}$. Besides reduction of systolic and diastolic BP $(22.5 / 7.2 \mathrm{mmHg}$ at 1 month and $27.8 / 8.8 \mathrm{mmHg}$ at 6 months, $P<0.001$ at each time point), RDN significantly reduced mean interventricular septum thickness from $14.1 \pm 1.9 \mathrm{~mm}$ to $13.4 \pm 2.1 \mathrm{~mm}$ and $12.5 \pm$ $1.4 \mathrm{~mm}(P<0.007)$. Ejection fraction significantly increased after RDN (baseline: $63.1 \pm 8.1 \%$ versus $70.1 \pm 11.5 \%$ at 6 months, $P<0.001)$. In 18 matched control patients, there were no significant changes [33]. This study suggests that RDN facilitates regression of left ventricular hypertrophy in patients with RH. Since patients with heart failure often have hyperactivity of the sympathetic nervous system, RDN may reduce future risks of these patients.

Clinical trial data from Symplicity radiofrequency catheter systems have created much interest in the role of the renal nerves in hypertension and other cardiovascular conditions. Furthermore, the attenuation of BP observed has led to the rapid development of alternative methods of RDN by radiofrequency ablation as well as by ultrasound ablation and perivascular pharmacologic ablation [34, 35]. Many clinical trials investigating these various innovative approaches to achieve $\mathrm{RDN}$ are ongoing.

\section{Conclusions}

Catheter-based RDN constitutes a novel treatment for RH. The two seminal studies which have evaluated this procedure in RH patients have demonstrated its safety and efficacy. Hypertensive patients being considered for RDN should not be considered to be resistant unless pseudoresistance has been excluded with the use of ABPM and secondary causes of hypertension have been ruled out. Further investigations and followup are needed to determine the long-term durability of $\mathrm{RDN}$, the possible modification of circadian variation of $\mathrm{BP}$ after RDN, its efficacy in other diseases such as heart failure, stroke, and kidney failure, and its use in stage 1 hypertension. Currently, there are no clinical trial data available to indicate that RDN improves cardiovascular outcomes.

\section{Conflict of Interests}

Richard E. Katholi is a consultant and on steering committees for Medtronic Inc.

\section{References}

[1] W. L. Verloop, M. Voskuil, and P. A. Doevendans, "Renal denervation: a new treatment option in resistant arterial hypertension," Netherland Heart Journal, vol. 21, no. 2, pp. 95-98, 2013.

[2] World Health Organization, "Global Health Risks: Mortality and burden of disease attributable to selected major risks," Geneva, Switzerland, 2009, http://www.who.int/healthinfo/ global_burden_disease/GlobalHealthRisks_report_full.pdf.

[3] A. S. Go, D. Mozaffarian, V. L. Roger, E. J. Benjamin, J. D. Berry, and W. B. Borden, "Heart disease and stroke statistics-2013 update: a report from the American Heart Association," Circulation, vol. 127, no. 1, pp. e6-e245, 2013.

[4] A. V. Chobanian, G. L. Bakris, H. R. Black et al., "Seventh report of the joint national committee on prevention, detection, evaluation, and treatment of high blood pressure," Hypertension, vol. 42, no. 6, pp. 1206-1252, 2003.

[5] D. A. Calhoun, D. Jones, S. Textor et al., "Resistant hypertension: siagnosis, evaluation, and treatment a scientific statement from the american heart association professional education committee of the council for high blood pressure research," Hypertension, vol. 51, no. 6, pp. 1403-1419, 2008.

[6] S. D. Persell, "Prevalence of resistant hypertension in the United States, 2003-2008," Hypertension, vol. 57, no. 6, pp. 1076-1080, 2011.

[7] L. Sans Atxer and A. Oliveras, "Denervación simpática renal en la hipertensión arterial resistente," Medicina Clínica De Barcelona, vol. 140, no. 6, pp. 263-265, 2013.

[8] Y. Huan and D. L. Cohen, "Renal denervation: a potential new treatment for severe hypertension," Clinical Cardiology, vol. 36, no. 1, pp. 10-14, 2013.

[9] E. A. Prince, T. P. Murphy, and C. O. Hampson, "Catheter-based arterial sympathectomy: hypertension and beyond," Journal of 
Vascular and Interventional Radiology, vol. 23, no. 9, pp. 11251134, 2012.

[10] S. Mafeld, N. Vasdev, and P. Haslam, "Renal denervation for treatment-resistant hypertension," Therapeutic Advances in Cardiovascular Disease, vol. 6, no. 6, pp. 245-258, 2012.

[11] G. Thomas, M. H. Shishehbor, E. L. Bravo, and J. V. Nally, "Renal denervation to treat resistant hypertension: guarded optimism," Cleveland Clinic Journal of Medicine, vol. 79, no. 7, pp. 501-510, 2012.

[12] H. Krum, M. Schlaich, R. Whitbourn et al., "Catheter-based renal sympathetic denervation for resistant hypertension: a multicentre safety and proof-of-principle cohort study," The Lancet, vol. 373, no. 9671, pp. 1275-1281, 2009.

[13] M. D. Esler, H. Krum, P. A. Sobotka et al., "Renal sympathetic denervation in patients with treatment-resistant hypertension (The Symplicity HTN-2 Trial): a randomised controlled trial," The Lancet, vol. 376, no. 9756, pp. 1903-1909, 2010.

[14] E. E. Vink and P. J. Blankestijn, "Evidence and consequences of the central role of the kidneys in the pathophysiology of sympathetic hyperactivity," Frontiers in Physiology, vol. 3, article 29, 2012.

[15] G. F. DiBona and M. Esler, "Translational medicine: the antihypertensive effect of renal denervation," American Journal of Physiology: Regulatory Integrative and Comparative Physiology, vol. 298, no. 2, pp. R245-R253, 2010.

[16] M. P. Schlaich, D. Hering, P. Sobotka, H. Krum, G. W. Lambert, and E. Lambert, "Effects of renal denervation on sympathetic activation, blood pressure, and glucose metabolism in patients with resistant hypertension," Frontiers in Physiology, vol. 3, article 10, 2012.

[17] M. P. Schlaich, H. Krum, and P. A. Sobotka, "Renal sympathetic nerve ablation: the new frontier in the treatment of hypertension," Current Hypertension Reports, vol. 12, no. 1, pp. 39-46, 2010.

[18] R. E. Katholi and K. J. Rocha-Singh, "The role of renal sympathetic nerves in hypertension: has percutaneous renal denervation refocused attention on their clinical significance?" Progress in Cardiovascular Diseases, vol. 52, no. 3, pp. 243-248, 2009.

[19] D. L. Cohen and R. R. Townsend, "Renal denervation revisited: promising treatment for resistant hypertension?" Journal of Clinical Hypertension, vol. 13, no. 12, pp. 931-932, 2011.

[20] H. Krum, M. Schlaich, P. Sobotka, I. Scheffers, A. A. Kroon, and P. W. De Leeuw, "Novel procedure- and device-based strategies in the management of systemic hypertension," European Heart Journal, vol. 32, no. 5, pp. 537-544, 2011.

[21] M. P. Schlaich, P. A. Sobotka, H. Krum, E. Lambert, and M. D. Esler, "Renal sympathetic-nerve ablation for uncontrolled hypertension," New England Journal of Medicine, vol. 361, no. 9, pp. 932-934, 2009.

[22] M. D. Esler, H. Krum, and M. Schlaich, "Renal sympathetic denervation for treatment of drug-resistant hypertension: oneyear results from the Symplicity HTN-2 randomized, controlled trial," Circulation, vol. 126, no. 25, pp. 2976-2982, 2012.

[23] P. J. Ong, D. Foo, and H. H. Ho, "Successful treatment of resistant hypertension with percutaneous renal denervation therapy," Heart, vol. 98, no. 23, pp. 1754-1755, 2012.

[24] X. J. Jiang, T. Liang, H. Dong, M. Peng, W. J. Ma, and T. Guan, "Safety and short-term efficacy of renal sympathetic denervation in the treatment of resistant hypertension," Zhonghua $Y i$ XueZaZhi, vol. 92, no. 46, pp. 3265-3268, 2012.
[25] M. C. Brandt, S. Reda, F. Mahfoud, M. Lenski, M. Böhm, and U. C. Hoppe, "Effects of renal sympathetic denervation on arterial stiffness and central hemodynamics in patients with resistant hypertension," Journal of the American College of Cardiology, vol. 60, no. 19, pp. 1956-1965, 2012.

[26] C. S. Zuern, K. D. Rizas, C. Eick, C. Stoleriu, L. Bunk, and P. Barthel, "Effects of renal sympathetic denervation on 24-hour blood pressure variability," Frontiers in Physiology, vol. 3, article $134,2012$.

[27] A. Witkowski, A. Prejbisz, E. Florczak et al., "Effects of renal sympathetic denervation on blood pressure, sleep apnea course, and glycemic control in patients with resistant hypertension and sleep apnea," Hypertension, vol. 58, no. 4, pp. 559-565, 2011.

[28] A. Pathak, X. Girerd, M. Azizi, H. Benamer, J. M. Halimi, and P. Lantelme, "Expert consensus: renal denervation for the treatment of hypertension," Diagnostic and Interventional Imaging, vol. 93, no. 5, pp. 386-394, 2012.

[29] F. Mahfoud, T. F. Lüscher, B. Andersson, I. Baumgartner, R. Cifkova, and C. DiMario, "Expert consensus document from the European Society of Cardiology on catheter-based renal denervation," European Heart Journal, vol. 34, no. 28, pp. 21492157, 2013.

[30] H. Krum, "Catheter-based renal sympathetic denervation for resistant hypertension: durability of blood pressure reduction out to 24 months," Hypertension, vol. 57, no. 5, pp. 911-917, 2011.

[31] B. P. Geisler, B. M. Egan, J. T. Cohen, A. M. Garner, R. L. Akehurst, and M. D. Esler, "Cost-effectiveness and clinical effectiveness of catheter-based renal denervation for resistant hypertension," Journal of the American College of Cardiology, vol. 60, no. 14, pp. 1271-1277, 2012.

[32] M. Dorenkamp, K. Bonaventura, A. W. Leber, J. Boldt, C. Sohns, and L. H. Boldt, "Potential lifetime cost-effectiveness of catheter-based renal sympathetic denervation in patients with resistant hypertension," European Heart Journal, vol. 34, no. 6, pp. 451-461, 2013.

[33] M. C. Brandt, F. Mahfoud, S. Reda et al., "Renal sympathetic denervation reduces left ventricular hypertrophy and improves cardiac function in patients with resistant hypertension," Journal of the American College of Cardiology, vol. 59, no. 10, pp. 901909, 2012.

[34] C. Stefanadis, K. Toutouzas, A. Synetos et al., "Chemical denervation of the renal artery by vincristine in swine. A new catheter based technique," International Journal of Cardiology, vol. 167, no. 2, pp. 421-425, 2013.

[35] F. Streitparth, A. Walter, N. Stolzenburg, L. Heckmann, J. Breinl, and J. L. Rinnenthal, "MR-guided periarterial ethanol injection for renal sympathetic denervation: a feasibility study in pigs," Cardiovascularand Interventional Radiology, vol. 36, no. 3, pp. 791-796, 2013. 


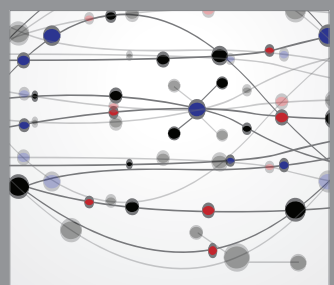

The Scientific World Journal
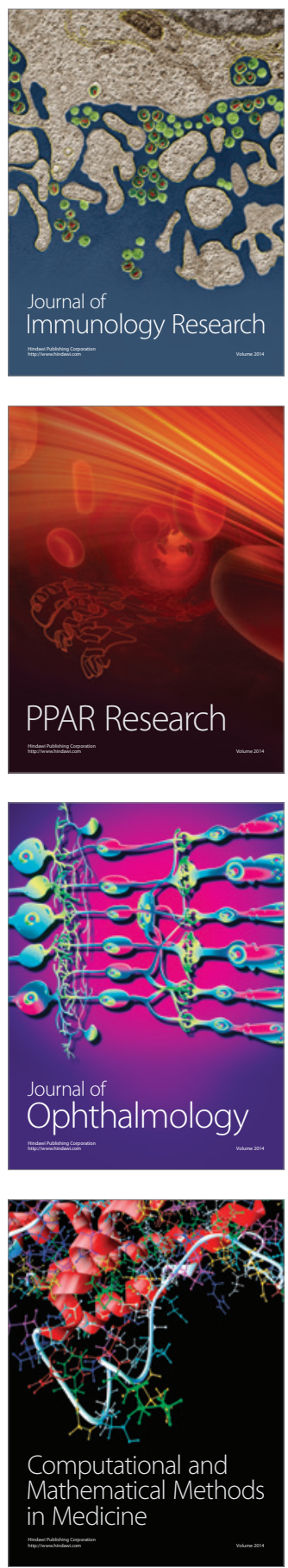

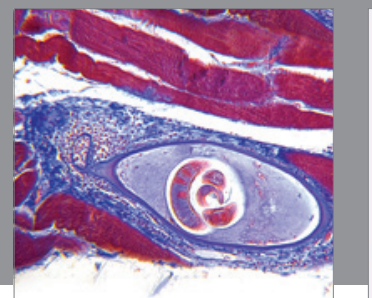

Gastroenterology

Research and Practice
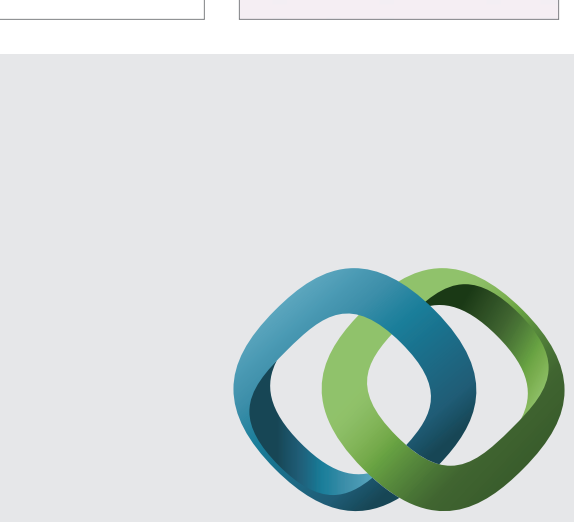

\section{Hindawi}

Submit your manuscripts at

http://www.hindawi.com
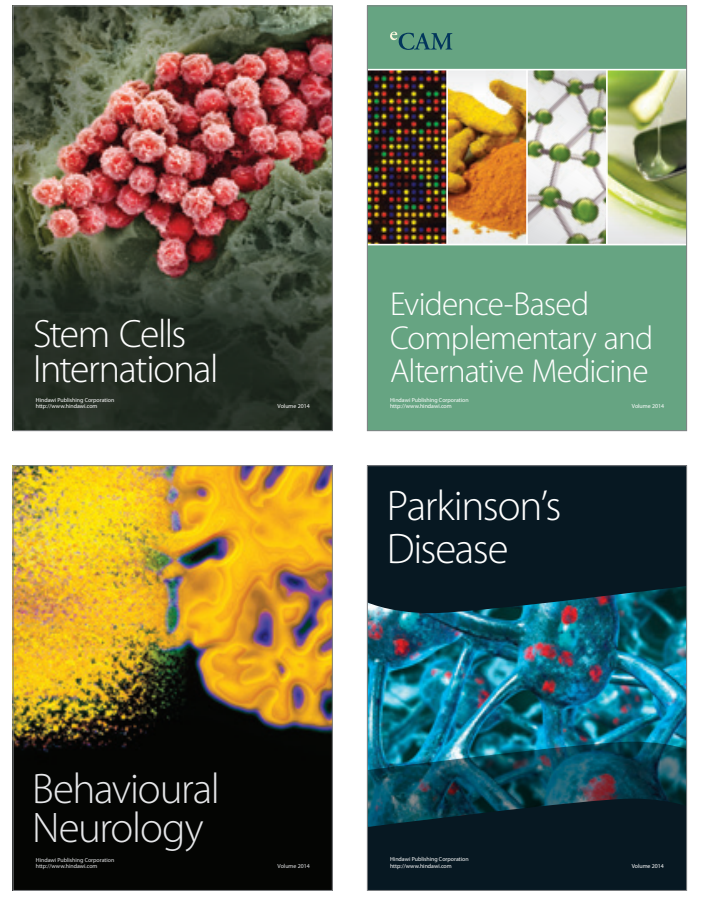
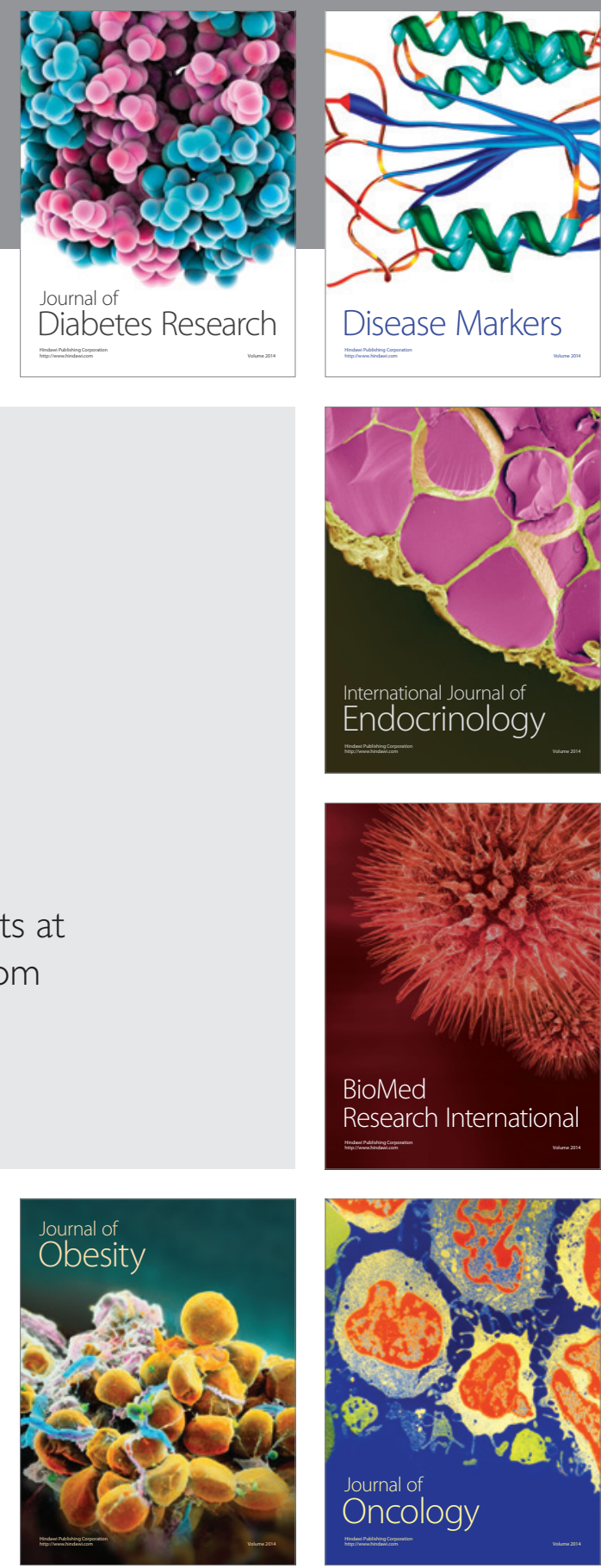

Disease Markers
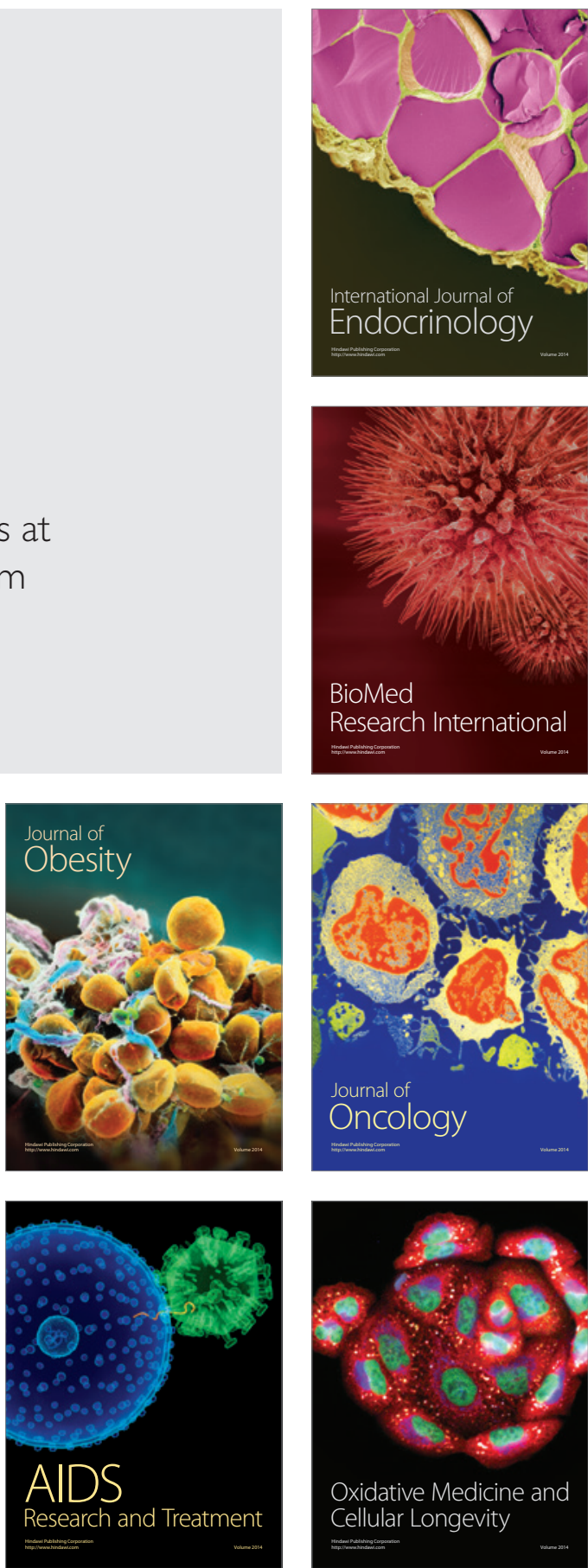